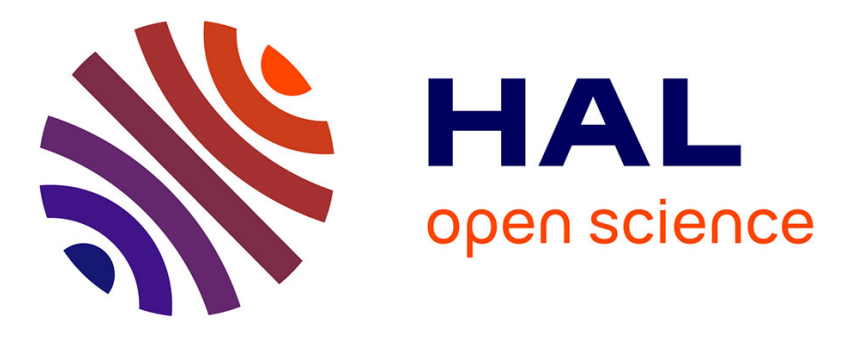

\title{
L-Band emission of rough surfaces: comparison between experimental data and different modeling approaches
}

Heather Lawrence, François Demontoux, Jean-Pierre Wigneron, Arnaud

Mialon, Tzong-Dar Wu, Valery Mironov, Liang Chen, Jianchen Shi, Yann H.

Kerr

\section{To cite this version:}

Heather Lawrence, François Demontoux, Jean-Pierre Wigneron, Arnaud Mialon, Tzong-Dar Wu, et al.. L-Band emission of rough surfaces: comparison between experimental data and different modeling approaches. MicroRad 2010, Mar 2010, Washington, United States. 6 p. + poster. hal-02821695

\section{HAL Id: hal-02821695 \\ https://hal.inrae.fr/hal-02821695}

Submitted on 6 Jun 2020

HAL is a multi-disciplinary open access archive for the deposit and dissemination of scientific research documents, whether they are published or not. The documents may come from teaching and research institutions in France or abroad, or from public or private research centers.
L'archive ouverte pluridisciplinaire HAL, est destinée au dépôt et à la diffusion de documents scientifiques de niveau recherche, publiés ou non, émanant des établissements d'enseignement et de recherche français ou étrangers, des laboratoires publics ou privés. 


\title{
L-BAND EMISSION OF ROUGH SURFACES: COMPARISON BETWEEN EXPERIMENTAL DATA AND DIFFERENT MODELING APPROACHES
}

\author{
Heather Lawrence ${ }^{1,2}$, François Demontoux ${ }^{1}$, Jean-Pierre Wigneron ${ }^{2}$, Arnaud Mialon ${ }^{3}$, Tzong-Dar $\mathrm{Wu}^{4}$,
} Valery Mironov ${ }^{5}$, Liang Chen ${ }^{6}$, Jianchen Shi ${ }^{6}$, Yann Kerr $^{3}$

\author{
${ }^{1}$ University of Bordeaux 1 - Laboratory IMS UMR 5218 - MCM department, Bordeaux, France \\ ${ }^{2}$ INRA-EPHYSE, Villenave d'Ornon, France \\ ${ }^{3}$ Centre d'Etudes Spatiales de la Biosphère (CESBIO), Toulouse, France \\ ${ }^{4}$ Department of Electrical Engineering National Taiwan Ocean University, Keelung, Taiwan \\ ${ }^{5}$ Kirensky Institute of Physics, Siberian Branch, Russian Academy of Sciences, Russia \\ ${ }^{6}$ Institute for Computational Earth System Science, University of California, Santa Barbara, USA
}

\begin{abstract}
In this paper we present a study of a numerical modeling approach based on the Finite Element Method (FEM) for the prediction of rough surface emission at L-band, including a comparison with other modeling approaches and experimental data. The numerical approach relies on the use of ANSYS' numerical computation software HFSS (High Frequency Structure Simulator), which in turn solves Maxwell's equations directly using the Finite Element Method. It is useful in the context of the SMOS (Soil Moisture and Ocean Salinity) mission since it can be extended to model the scattering and emission of heterogeneous media including complex multilayer systems such as the radiometric L-band emission of soil and litter layers in forests. In this paper we firstly validate the approach by comparing predictions of rough surface scattering against the Method of Moments (MoM). Secondly we study the accuracy of the numerical approach by comparing results of rough surface emissivity against measurements and predictions of the Advanced Integral Equation Method (AIEM).
\end{abstract}

Index Terms-Electromagnetic scattering by rough surfaces, microwave emissivity, numerical simulation, SMOS mission, soil-litter structures

\section{INTRODUCTION}

In the context of the European Space Agency's (ESA) Soil Moisture and Ocean Salinity (SMOS) mission [1], [2] we present a study of the emission of rough surfaces at 1.4 $\mathrm{GHz}$, including experimental data, predictions of the AIEM model [3] and predictions of a numerical modeling approach based on the Finite Element Method (FEM). Surface roughness has been studied in some depth in the literature as it is a key influencing parameter on ground emission. However there remains a need to further develop our understanding and modeling of its effects for applications such as the SMOS mission. In addition there is a need to extend studies of rough surface emission to include the volume effects of heterogeneous media and multilayer effects. One application of this is the investigation into the soil-litter system in forests, which has been shown to have an effect on L-band emission in forests but is as yet poorly understood [4], [5], [6].

The Method of Moments (MoM) [7], [8], [9] is a numerical method widely used for the calculation of rough surface scattering and emission since it is very accurate and well suited for the surface case. However it is not well suited to studies of heterogeneous media and it is therefore of interest to develop complimentary methods which can be more easily extended. It is in this context that we present an FEM numerical modeling approach. In this paper we validate the approach by comparison with predictions of the Method of Moments for the case of scattering from a bare rough surface. We then present a comparison of the approach with the commonly used AIEM analytical model[3] and experimental data from the SMOSREX 2006 campaign [10], [11], [12] in Toulouse.

\section{NUMERICAL MODELING APPROACH}

The numerical modeling approach relies on the use of ANSYS' HFSS $\odot$ (High Frequency Structure Simulator) (version 11.2) simulation software [13] which in turn solves Maxwell's equations using the Finite Element Method. The approach comprises three main stages: creating a solid structure with a rough surface and importing it into HFSS, using HFSS to calculate the electric field scattered off this structure, and finally calculating values of the bistatic scattering coefficient and emissivity from the scattered electric field. In this section we describe each of these three stages. 


\subsection{Calculation Area Set-Up}

A 3-dimensional layer with a rough surface is introduced into HFSS's calculation area by the following procedure. Randomly rough surfaces are generated in the form of $\{\mathrm{x}, \mathrm{y}, \mathrm{z}\}$ points using the " $\mathrm{R}$ " statistical software $\odot$, employing in particular the "Random Fields" package [14]. These rough surfaces have autocorrelation function of the following form:

$$
g(x, y)=\frac{1}{\sigma^{2}} \exp \left[-\left(\frac{\sqrt{x^{2}+y^{2}}}{L_{c}}\right)^{n}\right]
$$

where $\sigma$ is the standard deviation of the surface height and $\mathrm{L}_{\mathrm{c}}$ is the autocorrelation length.

The value of $\mathrm{n}$ determines the type of autocorrelation function: for the special cases of exponential and gaussian autocorrelation functions it is equal to 1 and 2 respectively.

It is also possible to introduce roughness profiles measured experimentally. The rough surfaces, either those created using the statistical software or real profiles measured experimentally, are then transformed into 3-dimensional layers as described in Fig. 1. C4W's "3D Shop Model Design" (C) software [15] is used to create solid slabs out of the rough surfaces.

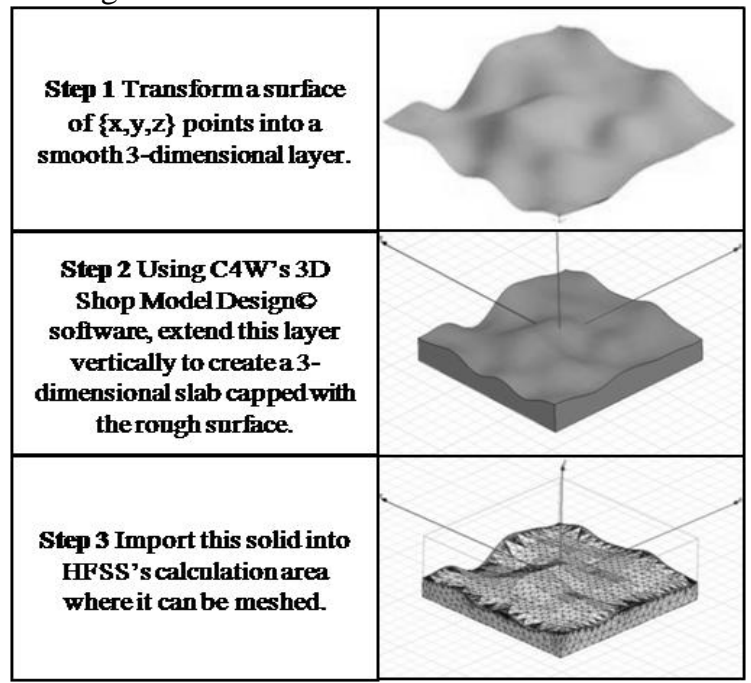

Fig. 1. Procedure for creating a 3D structure with a rough surface

The procedure described in Fig. 1 can be repeated any number of times in order to create a multilayer structure with rough surfaces in the calculation area, which is then surrounded by a vacuum. Once this structure has been created a dielectric permittivity constant $\left(\varepsilon_{\mathrm{r}}\right)$ is applied to each layer. Soil and litter layers can therefore be modeled as dielectric layers. The soil moisture can be introduced into the model as a function of the relative dielectric permittivity constant of the soil layer, either using models such as those developed by Dobson et al [16] or Mironov et al [17] or using a relationship found experimentally, such as [6].

\subsection{Numerical Calculation Conditions}

Once the structure to be studied has been introduced into the calculation area the calculation conditions can be defined. The calculation is set up for a continuous polarized incident wave, which can be either a plane wave or one of gaussian form, at an incident angle $\theta$ in the range of $0^{\circ}$ and $90^{\circ}$, and azimuth angle $\phi=0^{\circ}$. The calculation can be done for $\mathrm{H}$ or $\mathrm{V}$ polarization. Below the structure, a layered impedance boundary condition is applied to simulate an infinitely deep lower layer, preventing any reflections at the lower boundary of the structure. At the top and sides of the calculation area radiation boundary conditions are applied which also prevent reflections, as well as providing "virtual surfaces" for the near to far field calculation.

The scattered electric field $\left(\mathrm{E}_{\text {scattered }}\right)$ is calculated inside the area by HFSS using the Finite Element Method to solve Maxwell's equations. The electric field in the far field region, $\mathrm{E}_{\mathrm{r}}^{\mathrm{s}}\left(\theta_{\mathrm{s}}, \phi_{\mathrm{s}}\right)$, at a distance $\mathrm{R}$ from the surface is then extrapolated from this value at the virtual surfaces. Calculations were performed on a 64 bit machine with 4.5GB of available RAM.

\subsection{Data Analysis}

Numerical calculations are done for 20 different rough surfaces with the same autocorrelation functions and values of $\sigma$ and $\mathrm{L}_{\mathrm{c}}$. We then calculate the bistatic scattering coefficient, $\sigma_{r t}^{0}\left(\theta_{s}, \phi_{s} ; \theta, \phi\right)$, from the reflected electric field in the far field region, averaged over all the surfaces. This averaging process is done in order to approach the value that would be obtained for the case of an infinitely large rough surface. The bistatic scattering coefficient is calculated from the following [18]:

$$
\sigma_{r t}^{0}\left(\theta_{s}, \phi_{s} ; \theta, \phi\right)=\frac{4 \pi R^{2}}{A_{e f f}\left|E_{t}^{i}(\theta, \phi)\right|^{2}} \frac{1}{N} \sum_{i=1}^{N}\left|E_{r}^{s}\left(\theta_{s}, \phi_{s}\right)\right|^{2}
$$

where $(\theta, \phi)$ is the angle of the incident wave, $\left(\theta_{s}, \phi_{s}\right)$ is the angle of the reflected wave, $\mathrm{E}_{\mathrm{r}}^{\mathrm{s}}$ is the reflected electric field with polarization $\mathrm{r}, \mathrm{N}$ is the number of surfaces to be averaged over, $A_{\text {eff }}$ is the effective area of the surface illuminated and $\mathrm{E}_{\mathrm{t}}^{\mathrm{i}}$ is the incident electric field with polarization $t$, which for a gaussian incident wave has the following form:

$$
E_{t}^{i}=\exp \left[-\frac{\left(x-x_{\text {center }}\right)^{2}+\left(y-y_{\text {center }}\right)^{2}}{g^{2}}\right]
$$

where $(\mathrm{x}, \mathrm{y})$ is a point on the surface, $\left(\mathrm{x}_{\text {center }}, \mathrm{y}_{\text {center }}\right)$ is the center of the surface and $\mathrm{g}$ is a measure of the beam width. For this type of incident wave the effective area is given by 
$A_{\text {eff }}=\pi g^{2} / 2$ [8] and for a plane wave it is simply the area of the surface illuminated. The values of $\mathrm{g}$ and $\mathrm{N}$ must be carefully chosen. The emissivity of the surface measured at polarization $r, e_{r}(\theta, \phi)$, can be calculated by integrating the bistatic scattering coefficient over half space (Peake 1959), as follows [18]:

$$
e_{r}(\theta, \phi)=1-\Gamma_{r}(\theta, \phi)
$$

Where $\Gamma_{\mathrm{r}}(\theta, \phi)$ is the system reflectivity at polarization $\mathrm{r}$, given by:

$$
\begin{gathered}
\Gamma_{r}(\theta, \phi)=\frac{1}{4 \pi} \iint_{\substack{\text { hemisphere } \\
\text { nem }}} \frac{1}{\cos \theta}\left[\sigma_{r r}^{0}\left(\theta_{s}, \phi_{s} ; \theta, \phi\right)\right. \\
\left.+\sigma_{t r}^{0}\left(\theta_{s}, \phi_{s} ; \theta, \phi\right)\right] \sin \theta_{s} d \theta_{s} d \phi_{s} .
\end{gathered}
$$

\section{SMOSREX 2006 EXPERIMENTAL DATASET}

A long-term dataset was acquired over the course of 2006 at the SMOSREX site near Toulouse in the south of France, which has been in operation since January 2003 [10]. Details of the SMOSREX site including the equipment used have been presented in detail in [10] and the 2006 campaign in [11] and [12] and so here we will outline only the general method of the 2006 campaign.

On the 13th January 2006 the field on the SMOSREX site was ploughed to create a rough surface. It was then left to smooth out naturally over the course of the year. During this time L-band brightness temperature measurements were taken automatically every 3 hours, at $\mathrm{V}$ and $\mathrm{H}$ polarization and at angles of $20^{\circ}, 30^{\circ}, 40^{\circ}, 50^{\circ}$ and $60^{\circ}$, using the L-band radiometer for Estimating Water In Soils (LEWIS) installed on the site [10]. The LEWIS radiometer is mounted at the top of a $13.7 \mathrm{~m}$ vertical tower, and measures brightness temperature at $1.4 \mathrm{GHz}$ with an accuracy of $\pm 0.2 \mathrm{~K}$ and a beam-width of $13.5^{\circ}$.

Measurements of the soil moisture were taken throughout the year and soil temperature and weather conditions were also continuously monitored. Soil moisture was measured automatically every 30 minutes using impedance sensors (ML2 Theta probes) installed in the ground at depths of up to $90 \mathrm{~cm}$ and these probes were calibrated regularly with gravimetric measurements for a large range of soil moisture conditions. Soil temperature was also measured automatically every 30 minutes using thermistors at depths from 0 to $60 \mathrm{~cm}$. The site is equipped with a complete meteorological station that measured weather conditions, including measurements of precipitation, air temperature, atmospheric pressure, surface fluxes, wind speed and direction, infrared and solar radiation, and specific humidity every $2 \mathrm{~min}$ (averaged over $30 \mathrm{~min}$ ).

In order to monitor the evolution of the surface roughness over time, 2-D profiles of the ground surface were taken on
10 different days throughout 2006, including before ploughing, and once in January 2007. To do this a $2 \mathrm{~m}$ needle board with 201 needles, movable in the vertical direction and with $1 \mathrm{~cm}$ spacing between needles, was used, as described in [10] and [11]. The needle board was placed level above the surface and the needles allowed to fall until they touched the ground. Photos were then taken of the profile created by the needle heights and these photos digitized manually and finally used to compute soil topography profiles of $f=[x j, z j](j=1, \ldots, N), N=201$. For each day that this was done, 6-8 different profiles were taken in different positions on the site, both perpendicular and parallel to the furrows created by the plough.

\section{AIEM MODEL}

The Advanced Integral Equation Method (AIEM) was developed to produce an analytical solution for the rough surface reflectivity and emissivity, producing accurate results for a given region of validity.

The reflectivity is expressed as the sum of the coherent component $\left(\Gamma_{\text {coh }}\right)$ and the non-coherent component $\left(\Gamma_{\text {noncoh }}\right)$, i.e.:

$\Gamma=\Gamma^{c o h}+\Gamma^{\text {noncoh }}$

where $\Gamma \mathrm{p}^{*}(\theta)$ is the Fresnel reflectivity.

The non-coherent component is calculated from the bistatic scattering coefficient, applying (2), and the coherent component is approximated to the Fresnel reflectivity reduced by an exponential factor, given by (7) as follows:

$\Gamma^{c o h}=\Gamma_{p}^{*}(\theta) \exp \left[-(4 \pi \sigma \cos \theta / \lambda)^{2}\right]$

where $\lambda$ is the wavelength.

The bistatic scattering coefficient is rewritten as the sum of three terms: the Kirchoff term (from the Kirchoff Approximation), the cross term and the complimentary term. These three terms depend on rough surface properties $\sigma$ and $L_{c}$, the incident angle $(\theta)$, the surface dielectric permittivity constant $(\varepsilon)$ and the autocorrelation function, which can be either exponential or gaussian. These are the input parameters for AIEM.

AIEM is based on assumptions and so is limited to a validity region. In addition it is a surface scattering approach and so its use is limited to rather wet soils, where volume effects are negligible. 


\section{METHOD AND RESULTS}

\subsection{Comparison of the FEM approach with the Method of Moments}

The bistatic scattering coefficient was calculated using the FEM model for a one-layer 3-dimensional rough surface with calculation conditions shown in Table I. An incident wave with incident electric field in the form of a gaussian, was set up with a width of $0.40 \mathrm{~m}$ such that the incident electric field had a value between $10^{-1}$ and $10^{-2}$ at the edge of the calculation area, thus reducing errors due to edge effects. Results were compared to the Method of Moments for a rough surface with a gaussian autocorrelation function and $\mathrm{k} \sigma=1 \mathrm{~kL}_{\mathrm{c}}=6$ and a permittivity of $\varepsilon_{\mathrm{r}}=4+1 \mathrm{j}$ [19], [20]. The bistatic scattering coefficient was then calculated from (2) and averaging was done over 20 different surfaces because it was found that increasing the number of surfaces beyond 20 did not greatly change the results. Results are shown for polarizations $\mathrm{HH}$ and VV in fig. 2. Results show a good general agreement between the two methods

\subsection{Comparison with experimental data and the AIEM model}

Results from the SMOSREX 2006 campaign were filtered to select values corresponding to high soil moisture conditions, i.e. for a soil moisture between $28 \%$ and $32 \%$. The emissivity was then calculated from the brightness temperature measurements divided by the ground temperatures. We compared results of the emissivity from SMOSREX against predictions of the FEM approach and the AIEM model for the highest roughness conditions (highest $\sigma$, lowest $\mathrm{L}_{\mathrm{c}}$ ). The input value of soil permittivity was calculated for soil moisture of $30 \%$ by applying the model developed by Mironov et al. For the AIEM model we performed calculations for both exponential and gaussian autocorrelation functions. For the FEM approach calculations were done for the same conditions shown in Table I except that an incident plane wave was used, as it was found that edge effects were less important for the emissivity calculation. A gaussian surface autocorrelation function was used. The comparison is presented in fig. 3 .

Results show that predictions of the FEM method are closer to the experimental data than the AIEM model, for the gaussian autocorrelation function. We also see that the AIEM model produces better predictions for an exponential autocorrelation function, as is to be expected since natural surfaces tend to have autocorrelation functions closer to exponential than gaussian in form.
TABLE I

Calculation Conditions

\begin{tabular}{|c|c|}
\hline Frequency & $1.4 \mathrm{GHz}$ \\
\hline number of surfaces, $\mathrm{N}$ & 20 \\
\hline surface size & $1.27 \mathrm{~m} \mathrm{x} 1.27 \mathrm{~m}$ \\
\hline number of points on a surface & $128 \times 128$ \\
\hline gaussian wave constant, $\mathrm{g}$ & $0.4 \mathrm{~m}$ \\
\hline
\end{tabular}
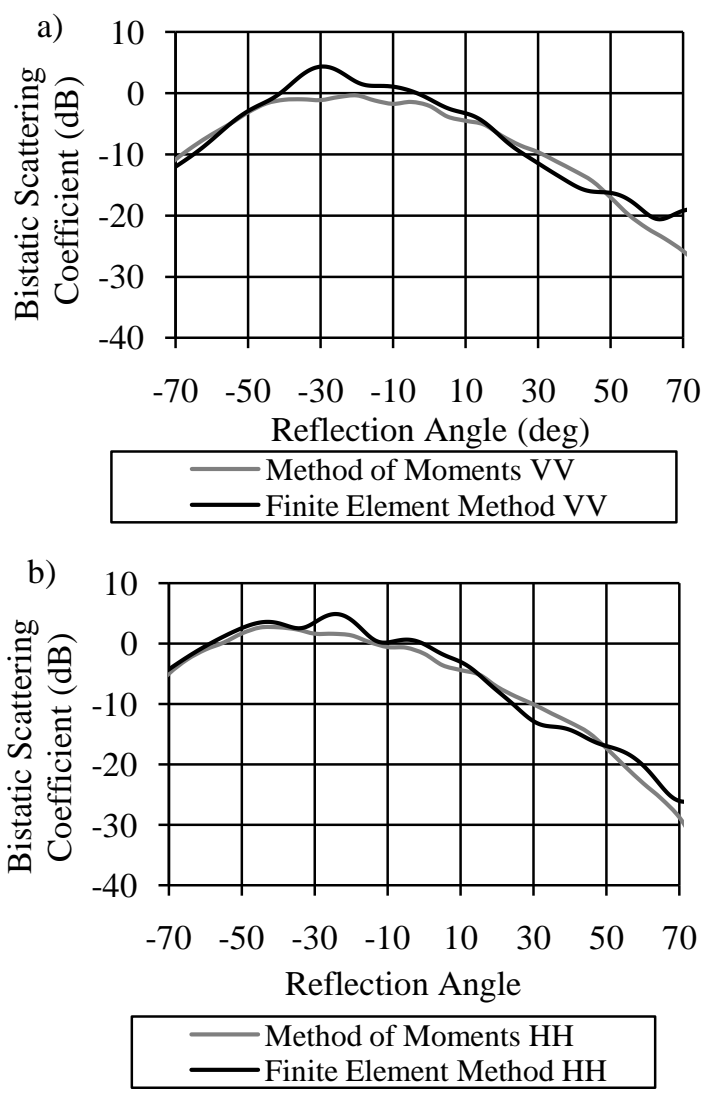

Fig. 2. Bistatic scattering coefficient for the Method of Moments and the Finite Element Method models, calculated for $\varepsilon_{\mathrm{r}}=4+1 \mathrm{j}$ and $\left[\mathrm{k} \sigma, \mathrm{kL}_{\mathrm{c}}\right]=[1,6]$ at polarizations a) $\mathrm{HH}$ and b) $\mathrm{VV}$ 

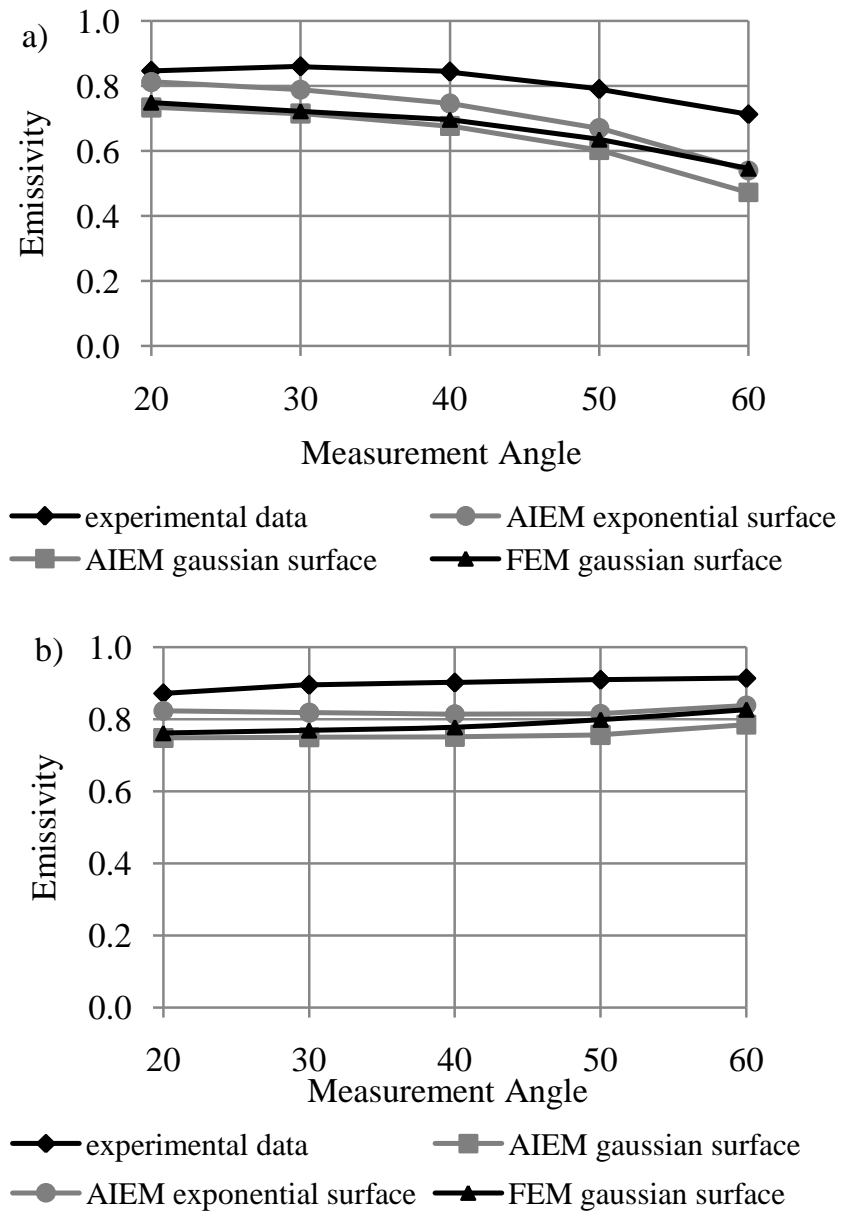

Fig. 3. Emissivity for the Finite Element Method and the AIEM model compared to the SMOSREX 2006 experimental data, for 30\% soil moisture, $\left[\mathrm{k} \sigma, \mathrm{kL}_{\mathrm{c}}\right]=[0.82,2.08]$ and at polarizations a) $\mathrm{H}$ and b) $\mathrm{V}$

\section{CONCLUSIONS}

We have presented an approach for the numerical calculation of rough surface scattering and emission using ANSYS' HFSS software which is in turn based on the Finite Element Method. We have found that this approach has a good agreement with the Method of Moments for the bistatic scattering case at low roughness and soil moisture conditions and a good agreement with measurements for the passive case at high roughness and high moisture conditions. Further work includes a wider study of the validity of the model, including exponential autocorrelation functions, and extending it to heterogeneous media and in particular the soil-litter forest medium.

\section{REFERENCES}

[1] Y.H. Kerr, P. Waldteufel, J.-P. Wigneron, J. Martinuzzi, J. Font, M. Berger, "Soil moisture retrieval from space: the Soil Moisture and Ocean Salinity (SMOS) mission," IEEE Trans. Geosci. Remote Sens., vol. 39, no. 8, pp. 1729-1735, Aug. 2001.
[2] M. Berger, Y. Kerr, J. Font, J.-P. Wigneron, J.-C. Calvet, K. Saleh, et al., "Measuring the moisture in the Earth's soil Advancing the science with ESA's SMOS Mission," ESA Bulletin, vol. 115 , pp. $40-45,2003$.

[3] Chen, K.S. and Chen, K.S. and Wu, Tzong-Dar and Tsang, Leung and Li, Qin and Shi, Jiancheng and Fung, A.K., "Emission of rough surfaces calculated by the integral equation method with comparison to three-dimensional moment method simulations," IEEE Trans. Geosci. Remote Sens., vol. 41, pp. 90-101, 2003

[4] J. P. Grant, J.-P. Wigneron, A. A. Van de Griend, A. Kruszewski, S. Schmidl Søbjærg and N. Skou, "A field experiment on microwave forest radiometry: L-band signal behaviour for varying conditions of surface wetness," Remote Sens. Environ., vol. 109, no. 1, pp. 10-19, Jul. 2007.

[5] M. Schwank, M. Guglielmetti, C. Matzler and H. Fluhler, "Testing a new model for the L-band radiation of moist leaf litter," IEEE Trans. Geosci. Remote Sens., vol. 46, no. 7, pp. 1982-1994, Jul. 2008.

[6] F. Demontoux, B. Le Crom, G. Ruffié, J.P. Wigneron, J.P. Grant, V.L. Mironov and H. Lawrence, "Electromagnetic characterisation of soil-litter media: Application to the simulation of the microwave emissivity of the ground surface in forests," $E P J$ Applied Physics, vol. 44, no. 3, pp. 303-315, Dec. 2008.

[7] R.M. Axline, A.K. Fung, "Numerical Computation of Scattering from a perfectly conducting Random Surface," IEEE Trans. Antennas Propag., vol. 26, no. 3, pp. 482-488, May 1978

[8] A.K. Fung, M.R. Shah and S. Tjuatja, "Numerical Simulation of Scattering from Three-Dimensional Randomly Rough Surfaces," IEEE Trans. Geosci. Remote Sens.,vol. 32, no. 5, pp 986-994, Sep. 1994.

[9] Q. Li, L. Tsang, J.C. Shi and C.H. Chan, "Application of physics-based two-grid method and sparse matrix canonical grid method for numerical simulations of emissivities of soils with rough surfaces at microwave frequencies," IEEE Trans. Geosci. Remote Sens., vol 38 pp 1635-1643, 2000

[10] P. de Rosnay, J. Calvet, Y. Kerr, J. Wigneron, F. Lemaître, M. Escorihuela, J. Sabater, K. Saleh, J. Barrié, G. Bouhours et al., "SMOSREX: A long term field campaign experiment for soil moisture and land surface processes remote sensing," Remote Sens. Environ., vol.102 (n 3-4), pp. p377-389, 2006.

[11] A. Mialon, J.-P. Wigneron, P. De Rosnay, M.J. Escorihuela and Y. Kerr, "Continuous monitoring of surface roughness changes over a bare soil field using L-Band brightness temperature," poster presentation at Microrad, Florence, Italy, Mar. 2008

[12] M. Schwank, I. Völksch, J.-P. Wigneron, Y. H. Kerr, A. Mialon, P. de Rosnay, and C. Mätzler, "Comparison of Two BareSoil Reflectivity Models and Validation With L-Band Radiometer Measurements," IEEE Trans. Geosci. Remote Sens., vol. 48, no. 1 pp. 325-337, Jan. 2010.

[13] http://www.ansoft.com/products/hf/hfss/ 
[14] R software website: http://www.r-project.org/, Random Fields package: http://cran.r-

Project.org/web/packages/RandomFields/RandomFields.pdf

[15] C4W's “3D Shop Modeldesign" product website: http://www.3dshopmodeldesign.com/

[16] M.C. Dobson, F.T. Ulaby, M.T. Hallikainen, M.A. El-Rayes, "Microwave Dielectric Behavior of Wet Soil-Part II: Dielectric Mixing Models", IEEE Trans. Geosci. Remote Sens., vol. 23, pp. 35-46, 1985.

[17] V.L. Mironov, L.G.Kosolapova and S.V. Fomin, "Physically and Mineralogically Based Spectroscopic Dielectric Model for Moist Soils," IEEE Trans. Geosci. Remote Sens., vol.47, no.7, pp.2059-2070, Jul. 2009.

[18] F.T. Ulaby, R.K. Moore and A.K. Fung, Microwave Remote Sensing, Active and Passive, vol. II. Dedham, MA: Artech House, 1985. Chapter 11-1.

[19] H.T. Ewe, J.T. Johnson and K.S.Chen, "A comparison study of the surface scattering models and numerical model," Proc. IGARSS, Sydney, Australia, pp. 2692 - 2694, 2001.

[20] H.T. Ewe, J.T. Johnson and K.S.Chen, "A Comparison Study of the Surface Scattering Models and Numerical Model" presentation at IGARSS, Sydney, Australia, July 13, 2001. 